\title{
Association of vaginal infections in Preterm labour
}

\author{
Srilakshmi Yarlagadda*, Sajana G., Prasuna J. L. Narra
}

Department of Obstetrics and Gynecology, Dr. Pinnamaneni Siddhartha Institute of Medical Sciences and Research Foundation, Chinoutapally, Krishna, Andhra Pradesh, India

Received: 01 May 2018

Accepted: 05 May 2018

\section{*Correspondence:}

Dr. Srilakshmi Yarlagadda,

E-mail: ysiri531@gmail.com

Copyright: ( $)$ the author(s), publisher and licensee Medip Academy. This is an open-access article distributed under the terms of the Creative Commons Attribution Non-Commercial License, which permits unrestricted non-commercial use, distribution, and reproduction in any medium, provided the original work is properly cited.

\section{ABSTRACT}

Background: Preterm labour is defined as onset of regular uterine contractions associated with cervical changes between 28-37 completed weeks of gestation. Prematurity is the cause of $85 \%$ neonatal morbidity and mortality. Preterm labour has multiple etiologies. Vaginal infections have been associated with increased risk for preterm labour. Screening for genitourinary infections antenatally, especially in high risk cases, prompt recognition and treatment decrease the incidence of preterm labour.

Methods: Ours was a prospective and retrospective observational study done at Dr. Pinnamaneni Siddhartha Institute of Medical Sciences and Research Foundation from April 2016 to February 2018 in the Department of Obstetrics and Gynaecology. The aim is to study the association of vaginal infections in preterm labour. A total of 116 women in preterm labor were studied. After clinical examination, CBP, CUE, Ultrasound, urine culture and sensitivity were done. Vaginal swab was taken from posterior fornix and sent for culture and sensitivity and gram staining .Culture and sensitivity were done in the Department of Microbiology at our Institute.

Results: Out of 116 women in preterm labour, urinary tract infection was seen in $27.58 \%$ women. E. Coli was the commonest microorganism isolated in urine (15.51\%). Vaginal infections were seen in $33.62 \%$ women. Candida was the commonest microorganism isolated in HVS cultures.

Conclusions: Screening for genitourinary infections in pregnancy is necessary, especially in high risk cases. Early detection and prompt treatment of genitourinary infections decrease the incidence of preterm labor, thereby decreasing the neonatal morbidity and mortality associated with prematurity.

Keywords: Preterm labour, Urinary tract infection, Vaginal infections

\section{INTRODUCTION}

Preterm labour is defined as onset of regular uterine contractions associated with cervical changes between 28 to 37 completed weeks of gestation.

Preterm birth is the leading cause of neonatal morbidity and mortality. $85 \%$ of neonatal morbidity and mortality is due to premature birth. The American Association of Paediatrics and ACOG 1997 proposed the following criteria to diagnose preterm labour.
- Uterine contractions of 4 in 20 minutes or 8 in 60 minutes plus progressive cervical changes.

- Cervical dilatation of $>1 \mathrm{~cm}$.

- Cervical effacement of $>80 \%$.

In the developed countries, the incidence of preterm birth is $5-10 \%$, whereas it is around $25 \%$ in developing countries. ${ }^{1}$ Worldwide incidence of premature birth ranges between $6-11 \% .^{2}$

Most of the times, the cause of preterm labour is unknown, but many conditions have been associated with 
an increased risk of preterm delivery. $30-40 \%$ of all cases of preterm birth are induced because of maternal or fetal complications. The remaining $60-70 \%$ are likely due to subclinical infective or inflammatory causes, especially genitourinary tract, cervical dysfunction, multiple gestations, idiopathic and possible social, environmental and nutritional interactions. ${ }^{3}$

The most serious outcome of preterm labour is often associated with adverse maternal and neonatal outcomes related to infection. ${ }^{4}$ Prostaglandins which are released because of infection stimulate uterine contractions leading to preterm labour. Preventive measures can prevent preterm labour and adverse neonatal outcome.

So, the present study was undertaken to study the role of vaginal infections in preterm labour. The main objective is to study the association of vaginal infections in preterm labour.

\section{METHODS}

This was a prospective and retrospective observational study done at Dr. Pinnamaneni Siddhartha Institute of Medical Sciences and Research Foundation from April 2016 to Feb 2018 in the Department of Obstetrics and Gynecology. The NICU at our hospital is well equipped and considering the facilities available in it, 28 weeks was taken as the lower limit for the period of viability in the present study.

Pregnant women between 28-37 weeks of gestation who set into spontaneous preterm labour only were included in the present study. Gestational age was assessed basing on the last menstrual period and dating scan.

Women who had uterine contractions of 4 in 20 min or 8 in $60 \mathrm{~min}$ associated with cervical dilatation of $\geq 1 \mathrm{~cm}$ and effacement of $>80 \%$ between $28-37$ completed weeks of gestation were included in the study.

\section{Inclusion criteria}

- Pregnant women between 28-37 completed weeks of gestation who set into spontaneous preterm labour.

\section{Exclusion criteria}

- Pregnant women with $<28$ weeks and $>37$ weeks of gestation.

- Pregnant women with APH

- Pregnant women with PROM

- Pregnant women with IUD

- Any pregnant woman whose pregnancy was terminated preterm for any maternal or fetal cause.

Written informed consent was obtained from enrolled women. Detailed history was taken with respect to age, parity, socioeconomic status, residence, previous pregnancy outcomes and for the presence of any risk factors in index pregnancy including genitourinary and respiratory infections, GDM, anaemia, hypertensive disorders, heart disease or any other medical disease, obstetric risks like hydramnios, multifetal gestation, malpresentation and uterine anomalies.

A thorough systemic and obstetric examination was done. Speculum examination was done to visualise cervix and vagina and to rule out cervical and vaginal infections.

Per vaginal examination was done to note cervical length and dilatation. CBP, CUE, Obstetric Ultrasound for cervical length, AFI, EFW, placental localisation and separation were done.

Swab from the posterior fornix of vagina was taken and sent for gram staining and culture sensitivity. Midstream urine sample was sent for culture and sensitivity.

Microbiological analysis and antimicrobial sensitivity testing of urine and high vaginal swab were done in the Department of Microbiology at our institute. All patients were monitored for features of sepsis like fever, maternal tachycardia, uterine tenderness and foul smelling vaginal discharge.

Since this study comes under descriptive statistics, results were analysed by calculating percentages.

\section{RESULTS}

In the present study, out of 2040 pts who delivered beyond 28 weeks between April 2016-Feb 2018, 116 women presented in preterm labour. The incidence of preterm labour at our institute was $5.68 \%$.

Table 1: Age.

\begin{tabular}{|lll|}
\hline Age $(\mathrm{N}=116)$ & $\mathbf{N o}$ & $\%$ \\
\hline$<20$ years & 38 & 32.75 \\
\hline 20-25 years & 26 & 22.41 \\
\hline 25-30 years & 22 & 18.96 \\
\hline 30-35 years & 20 & 17.24 \\
\hline 35 years & 10 & 8.62 \\
\hline
\end{tabular}

In the present study, majority of women who delivered preterm were in teenage $(32.75 \%)$.

Table 2: Gravida.

\begin{tabular}{|lll|}
\hline Gravida $(\mathbf{N}=116)$ & No & $\%$ \\
\hline Primigravidas & 25 & 21.55 \\
\hline G 2 & 27 & 23.27 \\
\hline G 3 & 46 & 39.65 \\
\hline G 4 & 18 & 15.51 \\
\hline
\end{tabular}

In the present study, $21.55 \%$ were primigravidas, $23.27 \%$ were second gravidas, $39.65 \%$ were third gravidas and $15.51 \%$ were fourth gravidas. 
Table 3: Booked/unbooked.

\begin{tabular}{|l|l|l|}
\hline Booked cases & 66 & 56.89 \\
\hline Unbooked cases & 50 & 43.10 \\
\hline
\end{tabular}

$56.89 \%$ were booked cases at our institute, but they had irregular antenatal checkups. $43.10 \%$ were unbooked cases.

Table 4: Socioeconomic status (SES).

\begin{tabular}{|lll|}
\hline SES $(\mathbf{N}=116)$ & No & $\%$ \\
\hline Lower & 47 & 40.51 \\
\hline Lower middle & 43 & 37.06 \\
\hline Upper middle & 16 & 13.79 \\
\hline Upper & 10 & 8.62 \\
\hline
\end{tabular}

It was evaluated according to Kuppuswamy classification. $40.51 \%$ belonged to lower SES, $37.06 \%$ to lower middle, $13.79 \%$ to upper middle and $8.62 \%$ to upper class.

Table 5: Body Mass Index (BMI).

\begin{tabular}{|lll|}
\hline BMI & No of cases & $\%$ \\
\hline Underweight & 52 & 44.82 \\
\hline Ideal & 36 & 31.03 \\
\hline Overweight & 16 & 13.79 \\
\hline Obese & 12 & 10.34 \\
\hline
\end{tabular}

Majority (44.82\%) had underweight in the present study. The weight gain during index pregnancy is also low.

Table 6: Residence.

\begin{tabular}{|ll|l|}
\hline Residence & No of cases & $\%$ \\
\hline Rural & 82 & 70.69 \\
\hline Urban & 34 & 29.31 \\
\hline
\end{tabular}

$70.69 \%$ lived in rural areas around the hospital and $29.31 \%$ lived in urban areas.

Table 7: Previous H/O abortions.

\begin{tabular}{|lll|}
\hline No. of abortions & No of patients & $\%$ \\
\hline One abortion & 16 & 13.79 \\
\hline Two abortions & 20 & 17.24 \\
\hline Three abortions & 9 & 7.75 \\
\hline
\end{tabular}

Table 8: Previous H/O preterm deliveries.

\begin{tabular}{|c|c|c|}
\hline No of prev preterm deliveries & $\begin{array}{l}\text { No of } \\
\text { patients }\end{array}$ & $\%$ \\
\hline $1 \mathrm{PTL}$ & 12 & 10.34 \\
\hline 2 PTL & 17 & 14.65 \\
\hline 3 PTL & 9 & 7.75 \\
\hline
\end{tabular}

It was observed in the present study that $38.79 \%(45 / 116)$ had previous $\mathrm{H} / \mathrm{O}$ one or more abortions. It has significant association with preterm labour in index pregnancy. $13.79 \%$ had previous one abortion, $17.24 \%$ had previous 2 abortions and $7.75 \%$ had previous 3 abortions.

$32.75 \%$ in the present study had previous history of one (or) more preterm deliveries. $10.34 \%$ had previous one preterm delivery, $14.65 \%$ had previous 2 preterm deliveries and $7.75 \%$ had previous 3 preterm deliveries. It has significant association with PTL in index pregnancy.

Table 9: Risk factors for preterm in index pregnancy.

\begin{tabular}{|lll|}
\hline Risk factor & No of cases & $\%$ \\
\hline UTI & 32 & 27.58 \\
\hline Vaginal infections & 39 & 33.62 \\
\hline GDM & 8 & 6.89 \\
\hline Anaemia & 24 & 20.69 \\
\hline Hypertensive disorders & 26 & 22.41 \\
\hline URTI & 18 & 15.51 \\
\hline Bronchial asthma & 5 & 4.31 \\
\hline Heart disease & 3 & 2.58 \\
\hline Pyrexia & 16 & 13.79 \\
\hline Multifetal gestation & 5 & 4.31 \\
\hline Hydramnios & 12 & 10.34 \\
\hline Uterine anomalies & 3 & 2.58 \\
\hline Malpresentations & 10 & 8.62 \\
\hline
\end{tabular}

It was observed that $74.13 \%(86 / 116)$ patients had one (or) multiple risk factors for preterm in index pregnancy. In the present study, $27.58 \%$ had UTI and $33.62 \%$ had vaginal infections, which was significant. $6.89 \%$ had GDM and $20.69 \%$ had anemia.

Hypertensive disorders were noted in $22.41 \%$. Upper respiratory tract infections were seen in $15.51 \%$. 3 patients had uterine anomalies, one with bicornuate uterus unicollis and 2 patients had septate uterus. $2.58 \%$ had congenital heart diseases and $4.31 \%$ had bronchial asthma. $13.79 \%(16 / 116)$ had fever, out of which 6 patients responded to antimalarials. $4.31 \%$ had twin pregnancies and $8.62 \%$ had malpresentations, the commonest being breech presentation. Hydramnios was seen in $10.34 \%$ cases.

Table 10: Bacteriological profile in urine sample

\begin{tabular}{|lll|}
\hline Micro organism & No of urine samples & $\%$ \\
\hline E. coli & 18 & 15.51 \\
\hline Klebsiella & 4 & 3.44 \\
\hline Candida & 3 & 2.58 \\
\hline Acinetobacter & 1 & 0.86 \\
\hline S.aureus & 6 & 5.17 \\
\hline Sterile & 68 & 58.62 \\
\hline Contaminated & 12 & 10.34 \\
\hline
\end{tabular}

UTI was seen in $27.58 \%$ cases. E. Coli was the commonest microorganism cultured in urine (15.51\%). 
Other microorganisms isolated were Klebsiella, Candida, Acinetobacter and Staphylococcus aureus.

Table 11: Bacteriological profile in vaginal samples

\begin{tabular}{|lll|}
\hline Microorganism & $\begin{array}{l}\text { No. of HVS } \\
\text { samples }\end{array}$ & $\%$ \\
\hline Candida & 36 & 31.03 \\
\hline $\begin{array}{l}\text { Staphylococcus } \\
\text { aureus }\end{array}$ & 1 & 0.86 \\
\hline Mixed microbes & 2 & 1.72 \\
\hline Sterile & 77 & 66.37 \\
\hline
\end{tabular}

Vaginal infection was seen in $33.62 \%$ cases which was significant. Candida was the commonest microorganism (31.03\%) seen in HVS cultures. Other organisms isolated were Staphylococcus aureus and mixed microbes.

\section{DISCUSSION}

In the present study, out of 2040 patients who delivered beyond 28 weeks between April 2016-Feb 2018, 116 cases presented in preterm labour. The incidence of preterm labour at our institute was $5.68 \%$. This is in close agreement to the world-wide incidence of preterm labour.

Fernandes $\mathrm{F}$ et al reported an incidence of preterm labour at $7.81 \%$ in their study. ${ }^{5}$ Beck $\mathrm{S}$ et al reported an incidence of 6 to $11 \%$ and Copper et al reported at 7 to $11 \% .^{2,6}$ However, Uma $\mathrm{S}$ et al in their study reported the incidence of preterm labour as $22 \% .^{7}$ The varied incidence in different studies may be due to differences in socioeconomic status, literacy and awareness of antenatal care among the pregnant women.

\section{Age}

Majority of women were in teenage in the present study (32.75\%). $22.41 \%$ were between 22-25years. Extremes of age group accounted for $41.37 \%$ cases. This is in comparison with the study done by Samim A et al in Iraq, 2006 , who reported that $36.5 \%$ of cases of preterm labour were in extremes of reproductive age group. ${ }^{8}$ In the study by Fernandes $\mathrm{F}$ et al. $^{5} 15.8 \%$ were in extremes of age group and $18.8 \%$ were in extreme age group in the study done by Renay Weiner et al in Kenya. ${ }^{9}$ This difference could be because more teenage and elder women were present in the present study.

\section{Gravida}

In the present study, $21.55 \%$ were primigravida and $78.44 \%$ were multigravidas.

In a longitudinal case series examining demographic and obstetric data of 17493 deliveries conducted in a referral centre in Israel by Shlomo E et al, preterm delivery rate was higher in grand multipara $(93 \%$ among grandmultipara). ${ }^{10}$ In the study by Fernandes F. et al. ${ }^{5}$ $45.11 \%$ were primigravidas and $54.39 \%$ were multigravidas. In the study done by Singh $U$ et al, $47 \%$ were primigravidas and $53 \%$ were multigravidas. ${ }^{7}$ Also, in a study conducted by Etuk SJ et al, $41.94 \%$ were primigravidas and $58.06 \%$ were multigravidas. ${ }^{11}$ The increased incidence of preterm labour in multigravidas in the present study could be because more number of younger women conceived with low interconception interval, malnutrition, anemia and genito-urinary infections.

In the present study, $56.89 \%$ were booked cases and $43.1 \%$ were unbooked cases. Though $56.89 \%$ were booked cases at our institution, they didn't come for regular antenatal checkups and so complications like anemia, UTI, genital infections, hypertensive disorders were more in them leading to preterm labour. $40.51 \%$ belonged to lower socioeconomic status and $37.06 \%$ to lower middle class. Because malnutrition, anemia and increased chances of infections were more in these women, the incidence of preterm labour was also high among them.

In the present study, $44.82 \%$ had underweight and majority $(70.69 \%)$ lived in rural areas. The incidence of anemia, malnutrition and genitourinary infections was also high in these women which might have led to preterm labour

\section{Past obstetric history}

In the present study, it was observed that $38.79 \%$ had previous $\mathrm{h} / \mathrm{o}$ abortion and $32.75 \%$ had previous $\mathrm{h} / \mathrm{o}$ preterm delivery which were significant.

In the study by Fernandes $\mathrm{F}$ et al $35 \%$ had previous h/o abortions and $12.11 \%$ had previous $\mathrm{h} / \mathrm{o}$ preterm births. ${ }^{5} \mathrm{In}$ a case control study done in Iraq by Samim A et al. ${ }^{8} 15 \%$ had h/o previous pretermbirths. In the study by Kiran P et al. ${ }^{12} 14.4 \%$ had previous h/o preterm births and $14.4 \%$ had previous $\mathrm{h} / \mathrm{o}$ abortions.

\section{Risk factors for preterm in index pregnancy}

Out of 116 women who delivered preterm in the present study, it was observed that 86 women $(74.13 \%)$ had one or more risk factors.

Vaginal infections were noted in $33.62 \%$ women in the present study. The commonest organism isolated in HVS cultures was Candida species. The other organisms were Staphylococcus aureus and mixed microbes.

In the study done by Pradeep Raju S et al the incidence of vaginal infections was $58.06 \%$ in women with preterm labour. ${ }^{13}$ Incidence of vaginal infections was high when compared to the study conducted by Fernandes $\mathrm{F}$ et al who reported an incidence of $8.29 \% .^{5}$ Samim A et al reported an incidence of $7.24 \%$ of women with vaginal infection in preterm labour. ${ }^{8}$ UTI was noted in $27.58 \%$ of cases. The commonest organism isolated was E. Coli 
$(15.51 \%)$. The other organisms isolated were Candida, Acinetobacter and S. Aureus.

Samim A et al reported $40 \%$ incidence of UTI in their study and Pandey Kiran et al. reported 20.34\% incidence of UTI in their study.,12 Fernandes $\mathrm{F}$ et al reported $13.65 \%$ incidence of UTI. The difference could be due to the differences in the criteria used to diagnose UTI, whether clinically based (or) by urine culture. ${ }^{5}$ Anemia was seen in $20.69 \%$ cases.

Hypertensive disorders were seen in $22.41 \%$ cases. This is comparable to the studies by Fernandes $\mathrm{F}$ et al, who reported an incidence of $21.07 \%$ of hypertensive disorders in preterm labour, Etuk SJ et al at $23.8 \%$. Shreshta $\mathrm{S}$ et al reported hypertensive disorders in preterm labour at $13.3 \%$ and Taskeen Rehana et al at $14 \%$ in their studies. ${ }^{5,11,14,15}$ The increased incidence of hypertensive disorders in the present study could be because, being a tertiary care centre with good NICU facilities, most of the women with high risk pregnancies were referred to our institute. GDM was seen in $6.89 \%$ In the present study. Shannon F. Fernandes et al reported an incidence of $3.41 \%$ in their study and Taskeen Rehana et al reported at $4 \% .^{5,15}$ Hydramnios was noted in $10.34 \%$ cases in the present study in contrast to the studies conducted by Fernandes F et al at $1.46 \%$, Shreshta S et al at $0.7 \%$ and Kiran $\mathrm{P}$ et al at $0.79 \% .^{5,12,14}$ Uterine anomalies were noted in $2.58 \%$ cases. One woman had bicornuate unicollis uterus and 2 had septate uterus. Kiran $\mathrm{P}$ et al reported uterine anomalies at $4.82 \%$ in their study. ${ }^{12}$ The difference may be because some uterine anomalies were not diagnosed before. Congenital heart disease (VSD with left to right shunt) was seen in $2.58 \%$ cases and bronchial asthma in $4.31 \%$ cases. $15.51 \%$ had upper respiratory tract infections in the present study which may be a causative agent for preterm labour. $13.79 \%$ cases had pyrexia. Out of which, 6 women responded to antimalarials and the rest had viral fever. Fever during the antenatal period is an important risk factor for preterm labor and IUD. Malpresentations were seen in $8.62 \%$ cases, commonest being breech presentation. Fernandes SF et al reported an incidence of $18.54 \%$ malpresentations in their study and Rehana $\mathrm{T}$ et al reported at $21 \%$. Malpresentation is an important risk factor for preterm labour. ${ }^{5,15} 4.31 \%$ had twin gestation in the present study which is a risk factor for preterm delivery. Fernandes SF et al reported twin gestation in their study at $9.77 \% .^{5}$

\section{CONCLUSION}

Prematurity is the cause of $85 \%$ neonatal morbidity and mortality. Vaginal infections significantly contribute to the preventable causes of preterm labor. It is always advisable to screen the antenatal women for the presence of asymptomatic genitourinary infections. Early recognition and prompt treatment of vaginal infections aid in the prevention of preterm labor and the associated neonatal morbidity and mortality of premature neonates.

\section{ACKNOWLEDGMENTS}

Authors would like to thank Dr. Vishnuvardhan Rao, Professor and HOD of the Department of Microbiology at our Institute for his support in conducting the study. Authors would like to thank Dr. Manogna and Dr. Sindhu, Postgraduates in the Department of Obstetrics and Gynecology at our institute for their help in conducting the study. Authors would like to thank all the patients and their attendants for their cooperation and contribution.

Funding: No funding sources

Conflict of interest: None declared

Ethical approval: The study was approved by the Institutional Ethics Committee

\section{REFERENCES}

1. Philip S. The epidemiology of preterm labour. BJOG. 2005;112:1-3.

2. Stacy B, Daniel W, Lale S, Ana PB, Mario M, Jennifer HR, et al . The worldwide incidence of preterm birth: a systematic review of maternal mortality and morbidity. Bull World Health Org. 2010;88:31-8.

3. Lumley J. Defining the problem: the epidemiology of preterm birth. BJOG. 2003;110:3-7.

4. Ziaei S, Sadrkhanlu M, Moeini A, Faghihzadeh S. Effect of bacterial vaginosis on premature rupture of membranes and related complications in pregnant women with a gestational age of 37-42 weeks. Gynecol Obstet Invest. 2006;61(3):135-8.

5. Shannon FF, Savita C. A study of risk factors for preterm labour. Int J Reprod Contracept Obstet Gynecol. 2015;4:1306- 12.

6. Copper RL, Goldenberg RL, Creasy RK, DuBard MB , David RO, et al . A multicenter study of preterm birth weight and gestational age specific neonatal mortality. Am J Obstet Gynecol.1993; 168:78-84.

7. Singh U, Singh N, Seth S. A prospective analysis of etiology and outcome of preterm labour. J Obstet Gynecol India. 2007;571:48-52.

8. Samim A Al-D, Wafa Y Al-T. Risk factors for preterm birth in Iraq: A case-control study. BMC Pregnan Childbir. 2006;6:13.

9. Renay W, Carine R, Ed D, Hilton J, Anne M, Caroline S. Labour complications remain the most important risk factors for perinatal mortality in rural Kenya. Bull World Health Organ.2003;81:561-6.

10. Shlomo E, Ehud W, Zohar N, Eliezer S. Epidemiological risk factors for preterm delivery.Isr Med Assoc J. 2002;4:1115-7.

11. Etuk SJ, Etuk IS, Oyo-ita AE. Factors influencing the incidence of preterm birth in Calabar ,Nigeria. Niger J Physiol Sci. 2005;20:63-8.

12. Pandey K, Bhagoliwal A, Gupta N, Katiyar G. Predictive value of various risk factors for preterm labour. J Obstet Gynaecol India. 2010;60:141-5. 
13. Pradeep S, Pallavi P, Navatha B, Krishna L.Vaginal infections and its relation to preterm labor, PPROM, PROM and its outcome. Int $\mathrm{J}$ Reprod Contracept Obstet Gynecol. 2015;4:1422-6.

14. Shresta S, Dangol SS, Shresta M, Shresta RPB. Outcome of preterm babies and associated risk factors in a hospital. $\mathrm{J}$ Nepal Med Assoc. 2010;50:286-90.
15. Taskeen R. Preterm delivery. A major predictor of perinatal morbidity and mortality. JPMI. 2006;20:279-83

Cite this article as: Yarlagadda S, Sajana G, Narra PJL. Association of vaginal infections in Preterm labour. Int J Reprod Contracept Obstet Gynecol 2018;7:2174-9. 